\title{
Testing for asset market linkages: a new approach based on time-varying copulas
}

Citation for published version (APA):

Manner, H., \& Candelon, B. (2007). Testing for asset market linkages: a new approach based on timevarying copulas. METEOR, Maastricht University School of Business and Economics. METEOR Research Memorandum No. 052 https://doi.org/10.26481/umamet.2007052

Document status and date:

Published: 01/01/2007

DOI:

10.26481/umamet.2007052

Document Version:

Publisher's PDF, also known as Version of record

\section{Please check the document version of this publication:}

- A submitted manuscript is the version of the article upon submission and before peer-review. There can be important differences between the submitted version and the official published version of record. People interested in the research are advised to contact the author for the final version of the publication, or visit the DOI to the publisher's website.

- The final author version and the galley proof are versions of the publication after peer review.

- The final published version features the final layout of the paper including the volume, issue and page numbers.

Link to publication

\footnotetext{
General rights rights.

- You may freely distribute the URL identifying the publication in the public portal. please follow below link for the End User Agreement:

www.umlib.nl/taverne-license

Take down policy

If you believe that this document breaches copyright please contact us at:

repository@maastrichtuniversity.nl

providing details and we will investigate your claim.
}

Copyright and moral rights for the publications made accessible in the public portal are retained by the authors and/or other copyright owners and it is a condition of accessing publications that users recognise and abide by the legal requirements associated with these

- Users may download and print one copy of any publication from the public portal for the purpose of private study or research.

- You may not further distribute the material or use it for any profit-making activity or commercial gain

If the publication is distributed under the terms of Article $25 \mathrm{fa}$ of the Dutch Copyright Act, indicated by the "Taverne" license above, 
Hans Manner, Bertrand Candelon

Testing for Asset Market Linkages: A new Approach based on Time-Varying Copulas

$\mathrm{RM} / 07 / 052$

JEL code: E32, F36

\section{METE@R}

Maastricht research school of Economics of TEchnology and ORganizations

Universiteit Maastricht

Faculty of Economics and Business Administration P.O. Box 616

NL - 6200 MD Maastricht

phone : ++31433883830

fax : ++31433884873 
December 11, 2007

\title{
Testing for Asset Market Linkages: A new Approach based on Time-Varying Copulas \\ by
}

\author{
Hans Manner ${ }^{1}$ and Bertrand Candelon ${ }^{2}$
}

\begin{abstract}
This paper proposes a new approach based on time-varying copulas to test for the presence of increases in stock market interdependence after financial crises, also known as shift-contagion process. We show that the previous approaches that take into account changes in volatility regimes are biased when the DGP is either copula based or when there is a break in variance significantly different from the one in correlation. A sequential algorithm is then elaborated to remove this bias. Applied to the recent 1997 Asian crisis, it confirms that breaks in variances always precede those in conditional correlation. It also turns out that this financial turmoil has been characterized by shift-contagion.
\end{abstract}

Keywords: Financial crisis; Contagion; Copula; Structural Change.

JEL Classification: E32, F36.

\footnotetext{
${ }^{1}$ Department of Quantitative Economics, Maastricht University, PoBOX 616, MD 6200, Maastricht, The Netherlands

${ }^{2}$ Corresponding author. Department of Economics, Maastricht University, PoBOX 616, MD 6200, Maastricht, The Netherlands, Tel.: +31 43 3883442; fax: +31 43 3884864; E-mail address: b.candelon@algec.unimaas.nl (B. Candelon)

*The authors thank Franz Palm, Stefan Straetmans and Jean-Pierre Urbain as well as the participants of the 2007 congress of the Method in International Finance Network for comments. The usual disclaimers apply.
} 


\section{Introduction}

The recent financial crises have renewed the debate on the importance of vulnerability of international financial markets and the propagation of foreign shocks. These turmoils originate from a crash in a "ground-zero" country ${ }^{3}$ which spreads across the world, even though market analysts considered other countries "healthy" before the crisis.

Financial market linkages are fostered by the trend towards an almost complete capital market liberalization (also called "globalization") and are consequently at the heart of the recent crises. Emerging countries wishing to finance domestic investments can find the capital they require on foreign capital markets. They are thus no longer bounded by their national saving and can then accelerate their growth. Nevertheless, it is achieved at the cost of a higher risk of financial instability: a negative shock in a "ground-zero" country will be quickly and strongly transmitted to its financial partners. The group of crisis-contingent theories explain the increase in market cross-correlation after a shock issued in a "ground-zero" country in several ways; multiple equilibria based on investor psychology, endogenous liquidity shocks causing a portfolio recomposition, and/or political disturbances affecting the exchange rate regime. The transmission of the crisis and the subsequent increase in cross correlation between markets is thus characterized by a "spill-over" or "shift-contagion" process. ${ }^{4}$ These crisis-contingent theories do not specify the channels of transmission, which are assumed to be unstable and crisis dependent. In contrast, the non-crisis-contingent theories consider that the propagation of shocks does not lead to a shift from a good to a bad equilibrium, but that the increase in cross-correlation is the continuation of linkages (trade and/or financial) existing before the crisis.

Empirical tests for "shift-contagion" avoid the identification of transmission channels and focus their attention on changing patterns of cross-market correlation. For example, the propagation of the Asian crisis from Thailand to Indonesia is revealed by a higher correlation

\footnotetext{
${ }^{3}$ Thailand and the devaluation of the Thai Bath in July 1997 is considered as the event that initiated the Asian crisis.

${ }^{4}$ Masson (1999) considers the particular case of "false" shift-contagion, where the increase in crosscorrelation may be due to the simultaneous occurrence of macroeconomic shocks across countries. According to the "monsoonal effect" theory, this artefact for shift-contagion is likely to happen as macroeconomic shocks are correlated.
} 
between these financial markets during the crisis period. This correlation breakdown has been considered by several empirical studies. For example, King and Wadhwani (1990) and Lee and Kim (1993) show that financial market cross-correlation in the largest financial markets exhibits a significant increase after the U.S. stock market crash. Similarly Calvo and Reinhart (1995) and Baig and Goldfajn (1998) offer similar results after the 1994 Mexican and the 1997 Asian crises.

The concept of "shift-contagion" appeared to be a robust standard stylized fact until the influential paper of Forbes and Rigobon (2002). Considering a simple linear framework they show that a any increase in spurious correlation is detected in the presence of a change in volatility. As during a crisis, financial markets are subject to high volatility regimes, Forbes and Rigobon (2002) propose a stability test for correlation, which is robust to volatility changes. Applied to the 1994 Mexican and the 1997 Asian crises, the hypothesis of higher cross-market linkages is ruled out. Several recent studies have extended the framework proposed Forbes and Rigobon (2002) (see among other Candelon et al, 2005 or Corsetti et al, 2005) without supporting the idea of absence of contagion.

The linear framework used in Forbes and Rigobon (2002) is also subject to strong criticism. Hartman et al (2004), Bae et al (2003) stress that contagion is not characterized by an increase in correlation over the whole sample, but only during a period of extreme events, i.e. a financial crises. It would support the idea that contagion is a transitory process and that dependence between markets deviates only temporarily from its long-run path. They consequently propose to test for an increase in tail dependence (also called "co-exceedence") around the financial crisis dates. ${ }^{5}$

Other studies (Ramchand and Susmel, 1998 and Ang and Beckaert, 2002 to name a few), prefer to consider another non-linear framework, namely the Markov-switching approach. They test for differences of the sample correlations among different volatility regimes identified as crisis and non-crisis periods. Maximum likelihood techniques are used to estimate the coefficients of a SWARCH and the probability matrix of staying or leaving a particular volatility regime.

More recently, Rodriguez (2007) investigates contagion using the concept of copulas. A Copula is the part of a joint distribution that completely describes its dependence structure. Copulas allow the modeling of the dependence between variables in a flexible way

\footnotetext{
${ }^{5}$ Formal tests for the stability tail-dependence are proposed in Straetmans (1997).
} 
and independently of the marginal distribution. They can then be used to analyze the dependence after certain events, of extreme events (tail dependence) and for losses and gains (asymmetric dependence). They thus appear to allow for a more general characterization of contagion than linear correlation. Moreover, the concept of time varying copulas by Patton (2006a) provides a tool that allows the degree and type of dependence to vary over time and to depend on a set of conditioning variables. Rodriguez (2007) follows a two-step approach. In a first step, univariate SWARCH models are estimated to determine the two volatility regimes: the low (resp. high) volatility regime corresponding to the non-crisis (resp. crisis) period. In a second step copula models are estimated, conditional on a dummy variable, representing the volatility regimes in the "ground-zero" country. The dependence parameters across the two volatility regimes are then compared using a standard likelihood ratio test.

This paper proposes to use copulas in order to investigate asset market shift-contagion. It is worth noticing that contagion is defined here as a significant increase in overall dependence, namely correlation, as in Forbes and Rigobon (2002). This point of view differs from Rodriguez (2007), who focuses on tail-dependence. Moreover, contrary to previous studies, we do not impose the dependence to have a break coinciding with the changes in volatility regime. ${ }^{6}$ It may be that both dates are identical, supporting the idea that change in dependence is synchronized with change in volatility regime. However, because of propagation time or information transfer, they are in our opinion unlikely to perfectly coincide. Anyway, the possibility to test for such an assumption is possible in the framework proposed in this paper. Besides, the Rodriguez (2007) two-step approach assumes that the volatility regimes are perfectly estimated via SWARCH (or any other methods which aim to detect changes in volatility). It is obvious that the error in estimating the transition probabilities ${ }^{7}$ should affect the second step results.

For this reason, this paper contributes to the literature by setting up a sequential algorithm. Based on a time varying copula, it allows for an efficient joint estimation of distinct breakpoints in dependence and volatility. Elaborating on Dias and Embrechts (2004), which

\footnotetext{
${ }^{6}$ A Preliminary analysis has shown that a variance dummy defined as in Rodriguez (2007) does not appear as significant in the conditional distribution of the copula. Results are available from the authors upon request.

${ }^{7}$ Rodriguez (2007) used the smooth transition probabilities, and a cut-off criterion to determine the regime timing. Both these choices are ad-hoc and a slight change might induce significant change in the results.
} 
proposes a formal test for the presence of a structural break in the dependence at an unknown period of time. The sequential algorithm also includes a formal estimation of the date of break in the variance parameters. ${ }^{8}$ Then, a Monte-Carlo study shows that the sequential algorithm we propose outperforms the Forbes and Rigobon (2002) method, which underestimates the presence of contagious events. It also outperforms Rodriguez (2007) copula based test, which accepts the increase in interdependence too often, when the structural break in variance is not causing the one in correlation. In the empirical application, which deals with the Asian 1997 crisis, it turns out that contagion, defined as an increase in correlation, is a dominating feature among the Asian economies. Furthermore, the assumption that dependence and volatility exhibit a simultaneous change in regime is rejected. The date of the change in regime is different, supporting the idea that transmission process may take some time after to the occurrence of a financial crisis.

The rest of the paper is organized as follows. Methodological tools are introduced in section 2. Section 3 is devoted to an extensive Monte-Carlo analysis. Section 4 presents the results of our empirical study in the case of the Asian crisis and section 5 offers some conclusions.

\section{Methodology}

\subsection{Copulas}

Copulas are multivariate distribution functions, which have uniform marginal distributions. They capture dependence between the random variables of interest independently of their marginal distributions and hence are scale invariant. Copulas find their applications mainly in finance when calculating the Value-at-Risk of a portfolio, pricing exotic options and credit derivatives, or for simply estimating the joint distribution of asset returns. ${ }^{9}$ In this study we only focus on bivariate copulas. Definitions and most results of univariate copulas carry over to the multivariate setting. In practice, however, the extensions are trivial only for

\footnotetext{
${ }^{8}$ The sequential algorithm does not have a formal estimation of the break in tail-dependence, which is assumed to be synchronous with the break in dependence.

${ }^{9}$ For a good exposition of financial applications of copulas see Cherubini et al. (2004). Applications in settings apart from measuring financial risk are rather rare and examples can be found in Granger et al. (2006) for modeling the income consumption relationship or Bonhomme and Robin (2004) who model earnings trajectories with the help of copulas.
} 
very specific cases. We thus limit the analysis to bivariate copulas. The most important result on copulas, Sklar's theorem, can be found with a proof in Nelson (2006) and states the following. Let $F$ be the marginal distribution function of $X, G$ be the marginal distribution function of $Y$, and let $H$ be the joint distribution function of $(X, Y)$. Then there exists a copula $C$ such that

$$
H(x, y)=C(F(x), G(y)), \forall(x, y) \in \overline{\mathbf{R}} \times \overline{\mathbf{R}},
$$

where $\overline{\mathbf{R}}$ denotes the extended real line. If $F$ and $G$ are continuous then $C$ is unique. Conversely if we have distribution functions $F$ and $G$ and a copula $C$, then $H$ is a bivariate distribution function. Recalling the probability integral transform for continuous distributions, which states that the random variable $U=F(X)$ has a $U(0,1)$ distribution regardless of the original distribution $F$, it becomes clear that a copula is no more than a multivariate distribution function with uniform marginals. ${ }^{10}$ It captures all the dependence between random variables of interest, as all the dynamics of the marginal distributions are captured by $F$ and $G$ for $X$ and $Y$, respectively. In the case of bivariate normal distribution, $F$ and $G$ are just normally distributed and the copula is completely described by the correlation between the margins. Other copulas allow for more complex and possibly non-linear dependence structures. For formal introductions to copulas and related functions, as well as a large number of examples of copulas we refer to the books by Joe (1997) and Nelson (2006). As correlation is the key feature of the paper, we will restrict our analysis to the Gaussian copula. ${ }^{11}$ It can easily be derived from the bivariate normal distribution and has the following distribution function

$$
C^{\text {Gaussian }}(u, v)=\int_{-\infty}^{\phi^{-1}(u)} \int_{-\infty}^{\phi^{-1}(v)} \frac{1}{2 \pi \sqrt{1-\rho^{2}}} \exp \left(-\frac{s^{2}-2 \rho s t+t^{2}}{2\left(1-\rho^{2}\right)}\right) d s d t
$$

where $\rho$ is the linear correlation coefficient of the corresponding bivariate normal distribution. Thus the dependence between two variables having a Gaussian copula is the correlation the variables would have if they had normal margins.

Patton (2006a) extended the theory by allowing the copula to be time varying and to depend

\footnotetext{
${ }^{10}$ Note that it is crucial that the marginal distributions are well specified so that the variables $F(x)$ and $G(y)$ are i.i.d. $U(0,1)$ distributed.

${ }^{11}$ Tail dependence can only be modeled by alternative types of copulas.
} 
on an exogenous conditioning set $\mathcal{F}_{t-1}$. In this way both the functional form of the copula and the copula parameter may vary over time. It is crucial, however, that the conditioning set is the same for marginal distributions as for the copula, otherwise the extension of Sklar's theorem to conditional distributions is not valid.

\subsection{The Model}

This paper opts for a model of contagion and interdependence between two asset markets, which consists in keeping the conditional mean process a simple linear process and in considering time-varying copula based distributions for the error terms, evolving with volatility and correlation regimes.

To this aim, the class of semiparametric copula-based multivariate dynamic (SCOMDY) models by Chen and Fan (2006) is considered. They propose a parametric estimation the conditional mean and variance of multivariate time series (using VAR or AR). In contrast, the multivariate distribution of the standardized innovations is estimated via a semiparametric copula model. The model for the conditional mean is given by the following stationary VAR model:

$$
\boldsymbol{R}_{t}=\Gamma(\boldsymbol{L}) \cdot \boldsymbol{R}_{t-1}+\epsilon_{t}
$$

where $\boldsymbol{R}_{\boldsymbol{t}}$ are the stacked returns in markets $r_{1}$ and $r_{2}, \boldsymbol{R}_{\boldsymbol{t}}=\left[\begin{array}{ll}r_{1}^{\prime} & r_{2}^{\prime}\end{array}\right]^{\prime}$ and $\boldsymbol{\Gamma}(\boldsymbol{L})$ is a lag polynomial with roots lying outside the unit circle. $\epsilon_{t}=\left(\epsilon_{1 t}, \epsilon_{2 t}\right)$ are the VAR errors which have the following conditional distribution:

$$
\left(\begin{array}{c}
\epsilon_{1 t} \\
\epsilon_{2 t}
\end{array}\right) \mid \mathcal{F}_{t-1} \rightsquigarrow C^{\text {Gaussian }}\left(F\left(\epsilon_{1} ; \boldsymbol{\eta}_{\boldsymbol{t}}\right), G\left(\epsilon_{2} ; \boldsymbol{\eta}_{\boldsymbol{t}}\right) ; \boldsymbol{\theta}_{\boldsymbol{t}}\right),
$$

where $\mathcal{F}_{t-1}$ is $\sigma$-space generated by the past returns. The variances of the marginal series $\sigma^{2}$ are included in the parameter vector $\boldsymbol{\eta}$, the copula or dependence parameter vector $\boldsymbol{\theta}$ reduces to the correlation $\rho$ in the case of a Gaussian copula. ${ }^{12}$ The marginal distributions

\footnotetext{
${ }^{12}$ Other copulas than the Gaussian one may be considered. Nevertheless, as we exclusively focus on the overall dependence parameter and we do not expect qualitatively different results we focus only on this types of copulas. Preliminary results suggested that using different copulas does not increase the fit considerably, once the dependence parameter is allowed to vary over time.
} 
$F$ and $G$ may be specified parametrically or non-parametrically. We model the marginals non-parametrically with the empirical distribution function

$$
\hat{F}(x)=\frac{1}{T} \sum_{t=1}^{T} \mathbf{1}_{\left\{X_{t} \leq x\right\}} .
$$

Two possibilities for the evolution of the time path of $\boldsymbol{\eta}_{\boldsymbol{t}}$ are considered. There may be a single unknown breakpoint in the level of volatility or the conditional variance can be modeled via a GARCH model. Similarly, the copula parameter $\boldsymbol{\theta}_{\boldsymbol{t}}$ can either be characterized by a single (unknown) breakpoint or can evolve over time, dynamically, as proposed in Patton (2006a), which will be described below. Both the breakpoints in volatility and in correlation are determined endogenously. Thus, changes in volatility and correlation induced by the regime shift are captured in the conditional distribution of the $V A R$ residuals.

Using copulas has three main advantages compared to using a known multivariate distribution such a the multivariate normal or student t-distribution. First, the individual series are likely to be not normally distributed (i.e. leptokurtic and skewed). The marginals underlying standard multivariate distributions do not allow for these features. Leaving the marginal distributions unspecified, eliminates the risk of misspecification, which may influence the estimation of the dependence parameter. ${ }^{13}$ Second, the dependence between two stock markets may show tail dependence (dependence of extreme losses), which may be modeled by several types of copulas. ${ }^{14}$ Third, using a copula representation as in (2) allows sequential estimation of marginal distribution as well as the copula itself. This leads to a significant decrease in the computing time.

A test for contagion can then be performed as follows: First, one looks for a breakpoint in the dependence parameter. If correlation does not increase, there is clearly no evidence for shift-contagion. When a breakpoint in the dependence parameter is detected, it may support the hypothesis of contagion, but it may also simply be due to an increase in volatility (see Forbes and Rigobon, 2002). To discriminate between these possibilities, several methods are available. First, it is possible to compare the confidence intervals of the breakpoint in variance in the "ground-zero" country and those of the breakpoint in correlation. Second,

\footnotetext{
${ }^{13}$ The advantage of not having to specify the marginal distributions comes at the cost of less efficient estimation of the copula parameter, see Genest et al. (1995).

${ }^{14}$ However, tail dependence analysis will not constitute the focus of this paper.
} 
the model (2) is extended to allow for the dependence parameter to vary over time, conditional on volatility. It then becomes possible to build a likelihood ratio test to determine whether the level or the regime of the conditional variance can explain the variation of the dependence parameter.

The tests for contagion based on correlation proposed by Forbes and Rigobon (2002) consist of estimating the $V A R$ model (2) ${ }^{15}$ and restricting the distribution of the error terms to a bivariate normal distribution, which is estimated over two predetermined periods (one preceding and the other one during the turmoil). A significant increase in the correlation of the error term during the turmoil (i.e. $\rho_{1}<\rho_{2}$ ) indicates the presence of contagion. Several studies have elaborated on this seminal paper keeping a similar framework. ${ }^{16}$ This approach suffers from several drawbacks. First, it may be subject to sample selection bias as the choice of tranquil and crisis periods is done beforehand. Second, the test assumed that the residuals are normally distributed. It is obvious that such a condition is violated in our case. Comparing the models before and during the crisis leads to the introduction of non-linearities, and transforms (2) into a regime-dependent model. Forbes and Rigobon (2002) associate these regimes to volatility stance, and propose a correction of the original test. It may nevertheless miss other explanatory factors and introduce again an endogeneity bias as the volatility regimes are determined beforehand.

Changes in dependence induced by the presence of volatility regimes have been explicitly modeled by Rodriguez (2007). ${ }^{17}$ He developed a two-step approach: First, dynamics in the mean are modeled via an $A R(1)$ model and volatility regimes $S_{t}$ are estimated for "groundzero" countries via a Markov-switching ARCH (SWARCH) approach. Then, the change in dependence (and tail-dependence) is investigated using copulas that are conditional on the

\footnotetext{
${ }^{15}$ Forbes and Rigobon (2002) also add interest rate as an exogenous control variable.

${ }^{16}(2)$ can be restated without adding more information as a common factor representation in order to separate the common factor from the idiosyncratic country-specific component. Corsetti et al. (2005) extract the common factor using principal components whereas Candelon et al. (2005) perform a common feature approach. The test for contagion boils down to a stability analysis of the common component. If its weight is larger after the crisis it can be concluded that shift-contagion occurred.

${ }^{17}$ A similar model has been developed by Okimoto (2007) to study the asset market linkages during bullish and bearish phases.
} 
volatility regime $s$ of the "ground-zero" country. Model (2) then becomes:

$$
r_{t}^{i}=\mu+\phi r_{t-1}^{i}+\epsilon_{t}^{i}
$$

where $\epsilon_{t}^{i}$ follows a $S W A R C H(2,1)$ process. The residuals $\nu_{t}^{i}$ of the $S W A R C H$ are modeled by flexible, fully parametric copula models, whose degree and type of dependence is conditioned on the state of the volatility regime $s_{t}$ :

$$
H\left(\nu_{t}^{1}, \nu_{t}^{2} \mid s_{t}\right)=C\left(F\left(\nu_{t}^{1} \mid s_{t}\right), G\left(\nu_{t}^{2} \mid s_{t}\right) \mid s_{t}\right)
$$

Rodriguez (2007) rationalizes the concept of copulas to investigate market tail-dependence and partially tackles the problem associated with the ad-hoc determination of volatility regimes in Forbes and Rigobon (2002). Nevertheless, it suffers from several drawbacks: First, it assumes that changes in dependence find their origin exclusively in volatility, which

might not always be the case. Second, even if the volatility regimes are estimated instead of being fixed, they are introduced in the unconditional model (second step) as known, without taking into account estimation uncertainty. Hence, the endogeneity bias is still present in this approach.

\subsection{Testing for structural breaks in copula models (Dias and Em- brechts, 2004)}

A formal test for the presence of a breakpoint in the dependence parameter of a copula is developed by Dias and Embrechts (2004). They assume a sample $\left(x_{1}, y_{1}\right) \ldots\left(x_{T}, y_{T}\right)$ where $t=1, \ldots . T$ generated by the bivariate distribution functions $H\left(x, y ; \boldsymbol{\theta}_{1}, \boldsymbol{\eta}_{1}\right) \ldots H\left(x, y ; \boldsymbol{\theta}_{T}, \boldsymbol{\eta}_{T}\right)$. The $\boldsymbol{\theta}_{t}$ 's are the parameters of the underlying copula, whereas the $\boldsymbol{\eta}_{t}$ 's are the parameters of the marginal distributions and are treated as nuisance parameters. Formally, the null hypothesis of no structural break in the copula becomes

$$
H_{0}: \boldsymbol{\theta}_{1}=\boldsymbol{\theta}_{2}=\ldots=\boldsymbol{\theta}_{T} \quad \text { and } \quad \boldsymbol{\eta}_{1}=\boldsymbol{\eta}_{2}=\ldots=\boldsymbol{\eta}_{T}
$$

whereas the alternative hypothesis of the presence of a single structural break is formulated as:

$$
H_{1}: \boldsymbol{\theta}_{1}=\ldots=\boldsymbol{\theta}_{k} \neq \boldsymbol{\theta}_{k+1}=\ldots=\boldsymbol{\theta}_{T} \equiv \boldsymbol{\theta}_{k}^{*} \quad \text { and } \quad \boldsymbol{\eta}_{1}=\boldsymbol{\eta}_{2}=\ldots=\boldsymbol{\eta}_{T}
$$


In the case of a known break-point $k$, the test statistics can be derived from a generalized likelihood ratio test. Let $L_{k}(\boldsymbol{\theta}, \boldsymbol{\eta}), L_{k}^{*}(\boldsymbol{\theta}, \boldsymbol{\eta})$ and $L_{T}(\boldsymbol{\theta}, \boldsymbol{\eta})$ be the log-likelihood functions of our copula given in (3) using the first $k$ observations, the observations from $k+1$ to $T$ and all observations, respectively. Then the likelihood ratio statistic can be written as

$$
L R_{k}=2\left[L_{k}\left(\hat{\boldsymbol{\theta}}_{k}, \hat{\boldsymbol{\eta}}_{T}\right)+L_{k}^{*}\left(\hat{\boldsymbol{\theta}}_{k}^{*}, \hat{\boldsymbol{\eta}}_{T}\right)-L_{T}\left(\hat{\boldsymbol{\theta}}_{T}, \hat{\boldsymbol{\eta}}_{T}\right)\right],
$$

where a hat denotes the maximizer of the corresponding likelihood function. Note that $\hat{\boldsymbol{\theta}_{k}}$ and $\hat{\boldsymbol{\theta}}_{k}^{*}$ denote the estimates of $\boldsymbol{\theta}$ before and after the break, whereas $\hat{\boldsymbol{\theta}}_{T}$ and $\hat{\boldsymbol{\eta}}_{T}$ are the estimates of $\boldsymbol{\theta}$ and $\boldsymbol{\eta}$ using the full sample. In the case of an unknown break date $k$, a recursive procedure similar to the one proposed by Andrews (1993) can be used. The test statistic is the supremum of the sequence of statistic for known $k$ :

$$
Z_{T}=\max _{1 \leq k<T} L R_{k}
$$

Dias and Embrechts (2004) recommend obtaining critical values using the approximation provided by Gombay and Horváth (1996), which we present here. Under $H_{0}$ it holds that for $T \rightarrow \infty$

$$
\left|Z_{T}^{1 / 2}-\sup _{1 / T \leq t \leq 1-1 / T}\left(\frac{B_{n}^{(d)}(T)}{t(1-t)}\right)^{1 / 2}\right|=o_{P}\left(\exp \left(-(\log (T))^{1-\varepsilon}\right)\right)
$$

for all $0<\varepsilon<1$, where $\left\{B_{T}^{(d)}: 0 \leq t \leq 1\right\}$ is a sequence of stochastic processes such that $\left\{B_{T}^{(d)}: 0 \leq t \leq 1\right\} \stackrel{d}{=}\left\{B^{(d)}: 0 \leq t \leq 1\right\}$ for each $T$ and $B^{(d)}(t)=\sum_{1 \leq i \leq d} B_{i}^{2}(t)$, where $\left\{B_{s}: 0 \leq t \leq 1\right\}, s=1, \ldots, d$ are independent Brownian bridges. There is no simple closed form expression for the distribution in (7). The following approximation can be used in practice. For $0<h<l<1$

$$
\begin{aligned}
P( & \left.\sup _{h \leq t \leq 1-l}\left\{\frac{B_{T}^{(d)}(t)}{t(1-t)}\right\}^{1 / 2} \geq x\right)=\frac{x^{d} \exp \left(-x^{2} / 2\right.}{2^{d / 2} \Gamma(d / 2)} \times \\
& \left(\log \frac{(1-h)(1-l)}{h l}-\frac{d}{x^{2}} \log \frac{(1-h)(1-l)}{h l}+\frac{4}{x^{2}}+\mathcal{O}\left(\frac{1}{x^{4}}\right)\right),
\end{aligned}
$$

as $x \rightarrow \infty$. Note that this limiting distribution is strictly identical to the one proposed in Andrews (1993), which applies in a more general context. The only difference is that Gombay and Horváth (1996) let the trimming parameters $l$ and $h$ depend on the sample size 
through $l(t)=h(t)=\log (t)^{3 / 2} / t$, whereas Andrews (1993) considers a constant trimming value. We thus opt for the use of the critical values tabulated by Andrews (1993) and to trim the first and last $15 \%$ of the observations.

\subsection{Testing for a structural break in volatility}

We test for a breakpoint in volatility using a quasi likelihood ratio test. To this end we model the return data with a normal distribution that has a structural break in variance at an unknown point in time $p$. Let $L_{p}(\sigma), L_{p}^{*}(\sigma)$ and $L_{T}(\sigma)$ be the log-likelihood function of the Gaussian distribution using the first $p$ observations, the observations from $p+1$ to $T$ and the whole sample, respectively. Again $\hat{\sigma}_{p}$ and $\hat{\sigma}_{p}^{*}$ stand for the estimates of $\sigma$ before and after the candidate breakpoint and $\hat{\sigma}_{T}$ is the estimate of $\sigma$ using the whole sample. Similar to the approach for testing for a breakpoint in correlation for

$$
L R_{p}=2\left[L_{p}\left(\hat{\sigma}_{p}\right)+L_{p}^{*}\left(\hat{\sigma}_{p}^{*}\right)-L_{T}\left(\hat{\sigma}_{T}\right)\right]
$$

the test statistic of interest is

$$
Z_{T}=\max _{1 \leq p<T} L R_{p}
$$

If one does not believe that the sample has a zero mean over the subsamples, then the series should be demeaned over the sub-periods. The asymptotic theory needed to study the behavior of the statistic $Z_{T}$ is the same as for the test above and the same critical values can be used.

Let $p$ be the point estimate for the breakpoint in variance. In order to obtain a confidence interval for this estimate we rely on a bootstrap procedure. We draw bootstrap samples from our data set before and after our estimated break $p$ and estimate from the bootstrap sample a breakpoint $p *$. This is repeated a sufficiently large number of times and the empirical $95 \%$ confidence interval is calculated from the sample of $p *$ 's.

\subsection{Jointly testing for structural breaks in volatility and depen- dence: a sequential algorithm}

The problem of testing for a structural break in the dependence parameter becomes more complicated when there is a breakpoint in the variances of the individual series. This is 
taken into account by considering the nuisance parameter $\boldsymbol{\eta}$, which may change at point $p$ under the alternative. Formally, the null hypothesis of our joint test is

$$
H_{0}: \boldsymbol{\theta}_{1}=\boldsymbol{\theta}_{2}=\ldots=\boldsymbol{\theta}_{T} \quad \text { and } \quad \boldsymbol{\eta}_{1}=\ldots=\boldsymbol{\eta}_{p}=\boldsymbol{\eta}_{p+1}=\ldots=\boldsymbol{\eta}_{T}
$$

versus

$H_{1}: \boldsymbol{\theta}_{1}=\ldots=\boldsymbol{\theta}_{k} \neq \boldsymbol{\theta}_{k+1}=\ldots=\boldsymbol{\theta}_{T} \equiv \boldsymbol{\theta}_{k}^{*} \quad$ and $\quad \boldsymbol{\eta}_{1}=\ldots=\boldsymbol{\eta}_{p} \neq \boldsymbol{\eta}_{p+1}=\ldots=\boldsymbol{\eta}_{T} \equiv \boldsymbol{\eta}_{p}^{*}$.

Thus under the alternative, a single break in both the dependence and the variance parameters occurs, and the breaks occur at different points in time $k$ and $p$. Therefore ideally both breaks must be estimated simultaneously. This is done by setting up a model based on a time-varying copula that allows for a break in the variances and in the dependence parameter. The supremum over all candidate breakpoints is chosen and the value of the likelihood ratio statistic is compared to the simulated critical value at a predefined nominal size. Assume without loss of generality that $p<k$ and let $L_{k \backslash p}(\boldsymbol{\theta}, \boldsymbol{\eta})$ be the likelihood function of the joint distribution in our model (3) using the observations between $p$ and $k$. In this situation the LR statistic becomes

$$
L R_{k, p}=2\left[L_{p}\left(\hat{\boldsymbol{\theta}}_{k}, \hat{\boldsymbol{\eta}}_{p}\right)+L_{k \backslash p}\left(\hat{\boldsymbol{\theta}}_{k}, \hat{\boldsymbol{\eta}}_{p}^{*}\right)+L_{k}^{*}\left(\hat{\boldsymbol{\theta}}_{k}^{*}, \hat{\boldsymbol{\eta}}_{p}^{*}\right)-L_{T}\left(\hat{\boldsymbol{\theta}}_{T}, \hat{\boldsymbol{\eta}}_{T}\right)\right]
$$

The test statistic then has the following form

$$
Z_{T}=\max _{\substack{1 \leq k<T \\ 1 \leq p<T}} L R_{k, p}
$$

This supremum statistics becomes more complicated when the variances of the two series exhibit a breakpoint at distinct points $p_{1}$ and $p_{2}$. In any case, the asymptotic distribution of the LR statistic $Z_{T}$ will also depend on the estimation of the breakpoint in the nuisance parameter $\boldsymbol{\eta}$. The approximations provided by Andrews (1993) and Gombay and Horváth (1996) should be modified to take the uncertainty in the estimation of the variance break into account.

Estimating all three breakpoints jointly is computationally very demanding and we opt for a sequential procedure to estimate the variance and dependence breaks. The copula decomposition of a joint distribution allows us to first estimate the marginal distributions, including the breakpoint in variance, followed by the estimation of the copula, which greatly 
reduces the computational burden. Strictly speaking we therefore apply a conditional test in the second step, estimating a breakpoint in the copula parameter, conditional on a break in the variance. The breaks in variance as well as the $95 \%$ confidence intervals $I_{p_{1}}$ and $I_{p_{2}}$ are estimated in a first step using the method introduced in section $2.4 .^{18}$ In a second step both series are transformed into uniform variables $(\tilde{u}, \tilde{v})$ such that $\tilde{u}=\hat{F}(x)$ and $\tilde{v}=\hat{F}(y)$. $\hat{F}(\cdot)$ is the empirical probability integral transform which has a different form before and after the estimated breaks $p_{1}$ and $p_{2}$ :

$$
\begin{aligned}
& \hat{F}_{p_{1}}(x)=\frac{1}{p_{1}} \sum_{t=1}^{p_{1}} \mathbf{1}_{\left\{X_{t} \leq x\right\}} \\
& \hat{F}_{p_{1}^{*}}(x)=\frac{1}{\left(T-p_{1}\right)} \sum_{t=p_{1}+1}^{T} \mathbf{1}_{\left\{X_{t} \leq x\right\}}
\end{aligned}
$$

and

$$
\begin{aligned}
& \hat{F}_{p_{2}}(y)=\frac{1}{p_{2}} \sum_{t=1}^{p_{2}} \mathbf{1}_{\left\{Y_{t} \leq y\right\}} \\
& \hat{F}_{p_{2}^{*}}(y)=\frac{1}{\left(T-p_{2}\right)} \sum_{t=p_{2}+1}^{T} \mathbf{1}_{\left\{Y_{t} \leq y\right\}}
\end{aligned}
$$

finally, the structural break test by Dias and Embrechts (2004) is applied to the transformed data $(\tilde{u}, \tilde{v})$. Thus, we compute a similar test statistic with the following form

$$
Z_{T}=\max _{1 \leq k<T} L R_{k}
$$

Assuming that the variance breaks are consistently estimated the resulting estimate (of the break in the correlation coefficient) is also consistent. However, the nuisance caused by the estimation error in the first step must be taken into account when obtaining the critical values for the sup $L R$ statistic in the second step. Furthermore, the stability may exhibit a size bias when the breaks are close to the trimming value (see Candelon and Lütkepohl, 2001). To tackle these potential problems the following parametric bootstrap algorithm is set up:

\footnotetext{
${ }^{18} p_{1}$ and $p_{2}$ refer to the breaks in the first and second series, respectively.
} 
1. Sequentially estimate the variance and correlation breaks $p_{1}, p_{2}$ and $k$ and store the confidence intervals $I_{p_{1}}$ and $I_{p_{2}}$ for the variance breaks.

2. Estimate the time constant copula parameter $\bar{\theta}$

3. Randomly draw two points $p_{1}^{\prime}, p_{2}^{\prime}$ for the variance breaks from the confidence intervals $I_{p_{1}}$ and $I_{p_{2}}$.

4. Estimate the variance $\sigma_{p_{i}^{\prime}}^{2}$ and $\sigma_{p_{i}^{\prime *}}^{2}$ before and after the drawn break for both series.

5. Generate two random series $(u, v)$ from a time constant copula $C(u, v ; \bar{\theta})$ and transform the marginal series into normal variables having the bootstrapped variance break and the variances estimated before and after that break. So $x_{t}=\Phi^{-1}\left(u ; \sigma_{p_{1}^{\prime}}^{2}\right)$ for $t \leq p_{1}^{\prime}$ and $x_{t}=\Phi^{-1}\left(u ; \sigma_{p_{1}^{\prime *}}^{2}\right)$ for $t>p_{1}^{\prime}$ and similarly for $y_{t}$.

6. Apply the sequential breakpoint test to this series and compute the sup LR $Z^{*}$ statistic for the correlation break.

7. Repeat steps 3-6 $m$ times ( $m$ being sufficiently large) and obtain the desired empirical quantile from the bootstrapped test statistics.

\section{Monte Carlo Studies}

In this section, we compare the properties of the Forbes and Rigobon (2002) test and the copula based and the sequential tests elaborated in section 2 with several types of stock market interdependencies.

\subsection{Monte Carlo Study 1:}

In this first experiment we investigate the behavior of a traditional copula test when the DGP is similar to the one presented in Forbes and Rigobon (2002). Stock market returns are assumed to be related according to the following linear DGP:

$$
x_{t}=\mu+\gamma_{1} x_{t-1}+\epsilon_{t},
$$


and

$$
y_{t}=\beta_{0}+\gamma_{2} y_{t-1}+\beta_{1} \epsilon_{t}+\nu_{t}
$$

where $t=1, \ldots, T$, and the error term $\nu_{t}$ is assumed to have zero mean, finite variance and to be uncorrelated with $\epsilon_{t}$. As it is now a well known stylized fact, that financial markets returns exhibit some volatility clusters, the (strongly) exogenous variable $x_{t}$ is assumed to follow a normal $G A R C H(1,1)$. Thus the conditional variance $h_{t}$ of $\epsilon_{t}$ is given by

$$
h_{t}=\omega_{t}+\alpha_{1} \epsilon_{t-1}^{2}+\alpha_{2} h_{t-1}
$$

As parameters for the $\operatorname{GARCH}(1,1)$ and the equation for $y_{t}$, we choose $\beta_{0}=0, \beta_{1}=0.35$, $\alpha_{1}=0.15$ and $\alpha_{2}=0.75$, which corresponds more or less to the estimated parameters of our empirical section. The difference between the pre- and post-crisis period lies in the value of $\omega_{t}$, which determines the conditional correlation between the markets: a high (resp. low) $\omega$ indicates a strong (resp. weak) interdependence between the markets. Concerning the dynamics characterized by $\left(\gamma_{1}, \gamma_{2}\right)$, two alternative specifications are investigated. First, $x_{t}$ and $y_{t}$ are imposed to have no short-run dynamics (i.e. $\gamma_{1}=\gamma_{2}=0$ and to have a 0 mean, so $x_{t}=\epsilon_{t}$. Alternatively, some dynamics is introduced into the DGP by setting $\gamma_{1}=0.3$ and $\gamma_{2}=0.5$. In the tranquil period (i.e. before the occurrence of a financial turmoil) $\omega_{t}$ is set equal to 0.1 , corresponding to a conditional correlation between $x_{t}$ and $y_{t}$ roughly equals to $\rho=0.3$. After the structural break $T_{b}$, which is known and fixed at a fraction of the sample $T / 2$, we examine the case where conditional correlation increases to roughly $\rho_{h}=0.5$, 0.7 and $0.9 .{ }^{19}$ The sample sizes $T$ are 500, 1.000 and 2.000 observations and the number of replications $N$ is fixed to $1.000 .^{20}$

The contagion test based on copulas is performed assuming that the break in variance is known and follows the following steps: Both the mean and the variance are estimated for the series before and after the break. ${ }^{21}$ The series are then transformed into $U(0,1)$ variable via the normal CDF. It is then possible to estimate a conditional gaussian copula on the

\footnotetext{
${ }^{19}$ The conditional correlation parameters corresponding to our parameter choices were obtained by simulation.

${ }^{20}$ Matlab random generator rand is used for the simulations and the same generated series are used to allow for fair comparison between the different cases. Programs are available from the authors upon request.

${ }^{21}$ For the dynamic DGP we work with the residuals of AR(1) regressions.
} 
transformed data, where the conditioning variable is a dummy for the second half of the sample: $D_{t}=0$ for $t<T / 2$ and $D_{t}=1$ for $t \geq T / 2{ }^{22}$ The correlation $\rho_{t}$ evolves as

$$
\rho_{t}=\Lambda\left(\alpha+\beta D_{2}\right)
$$

where $\Lambda(x)=\frac{1-e^{-x}}{1+e^{-x}}$ is the modified logistic transformation to keep $\rho$ in $(-1,1)$. The contagion test consists in testing the nullity of the coefficient of the dummy variable via a simple loglikelihood ratio test: $H_{0}: \beta=0$ (no contagion) vs $H_{1}: \beta \neq 0$ (contagion). In Table 1 , we report the rejection frequency of the null hypothesis. From these results, it is also possible to infer the influence of the dummy on the conditional correlation coefficient (Table 2). The nominal size is fixed to $5 \%$. The size of the test, which corresponds to the first line of Table 1 (conditional correlation is identical before and after the break date), is higher than the nominal size indicating a tendency to over accept the presence of change in conditional correlation (i.e. contagion). It turns out that the results of the simulation are similar when considering a DGP with or without dynamics. The size unadjusted power, on the other hand, is close to 1 indicating that the dummy coefficient captures quite well the effect the variance increase on the conditional correlation. To summarize, this first simulation exercise shows that when stock market returns are generated by the process suggested by Forbes and Rigobon (2002) a conditional copula model falsely detects a structural break in the correlation and then over-estimates the presence of contagion. Nevertheless, it is possible to measure the contribution of the change in variance in the increase in dependence. This could be useful to develop a correction for the contagion test.

\subsection{Monte Carlo Study 2}

Our second simulation exercise investigates the behavior of the Forbes and Rigobon (2002) test for contagion when the data is now generated by a Gaussian copula. ${ }^{23}$ The two i.i.d.

\footnotetext{
${ }^{22}$ This method is similar to Rodriguez (2007), who builds the conditional dummy variable from the "ground-zero" country.

${ }^{23} \mathrm{~A}$ similar simulation exercise can be done with other types of copulas. Result remains identical and can be obtained from the authors upon request.
} 
Table 1: Rejection frequency of the null hypothesis of constant correlation against the alternative that correlation increases conditional on volatility, Copula based contagion test, DGP (12) - (14)

\begin{tabular}{rrrrrrr}
\hline \hline & without dynamics & \multicolumn{4}{c}{ with dynamics } \\
& $\mathrm{T}=500$ & $\mathrm{~T}=1000$ & $\mathrm{~T}=2000$ & $\mathrm{~T}=500$ & $\mathrm{~T}=1000$ & $\mathrm{~T}=2000$ \\
\hline$\rho_{h}=0.3$ & 0.108 & 0.119 & 0.119 & 0.135 & 0.153 & 0.146 \\
$\rho_{h}=0.5$ & 0.790 & 0.956 & 0.999 & 0.746 & 0.922 & 0.977 \\
$\rho_{h}=0.7$ & 1 & 1 & 0.997 & 1 & 0.994 & 0.996 \\
$\rho_{h}=0.9$ & 1 & 1 & 0.999 & 0.947 & 0.945 & 0.944 \\
\hline \hline
\end{tabular}

Note: Table 1 reports the rejection frequency of the null hypothesis of nocontagion using copula based contagion test. The DGPs are defined by (13) to (13), the structural break is fixed at the middle of the sample and. The correlation before the break is 0.3 and after $\rho_{h}$. The number of replications $N$ is fixed to 1.000 .

Table 2: Average correlation due to the dummy capturing the regime change in variance.

\begin{tabular}{rrrrrrr}
\hline \hline & without dynamics & \multicolumn{4}{c}{ with dynamics } \\
& $\mathrm{T}=500$ & $\mathrm{~T}=1000$ & $\mathrm{~T}=2000$ & $\mathrm{~T}=500$ & $\mathrm{~T}=1000$ & $\mathrm{~T}=2000$ \\
\hline$\rho_{h}=0.3$ & -0.0005 & 0.0004 & -0.0021 & -0.0039 & -0.005 & -0.0008 \\
$\rho_{h}=0.5$ & 0.2017 & 0.2061 & 0.2049 & 0.1969 & 0.1995 & 0.1972 \\
$\rho_{h}=0.7$ & 0.4001 & 0.4009 & 0.3974 & 0.3822 & 0.3854 & 0.385 \\
$\rho_{h}=0.9$ & 0.5803 & 0.5812 & 0.5795 & 0.5229 & 0.5305 & 0.5298 \\
\hline \hline
\end{tabular}


series $x_{t}$ and $y_{t}$ are generated by $D G P_{2}$ :

$$
\begin{gathered}
\left(u_{t}, v_{t}\right) \sim C_{0.3}^{\text {Gaussian }}, \\
x_{t}=\Phi^{-1}\left(u_{t} ; 0,1\right), \\
y_{t}=\Phi^{-1}\left(v_{t} ; 0,1\right)
\end{gathered}
$$

before the break and by

$$
\begin{gathered}
\left(u_{t}, v_{t}\right) \sim C_{\rho_{h}}^{\text {Gaussian }}, \\
x_{t}=\Phi^{-1}\left(u_{t} ; 0, \sigma_{h}\right), \\
y_{t}=\Phi^{-1}\left(v_{t} ; 0, \sigma_{h}\right)
\end{gathered}
$$

after the break. By itself this is a rather simplistic DGP for stock returns, but one may think of it as generating the innovations for a $V A R$ as in the model we consider for the empirical application. The sample sizes $T$, the number of replications $N$, and the correlation before and after the turmoil period are the same as in the previous Monte-Carlo exercise. The first difference with respect to the previous Monte-Carlo analysis, is that we investigate the behavior of the test for several known dates of the structural break $T_{b}\left(T_{b}=(0.25,0.5,0.75)\right)$. Second, during the financial turmoil the standard deviation $\left(\sigma_{h}\right)$ of the series takes on the values 3, 5 and 10 larger than those before the structural break (fixed here to 1 ). The first value corresponds to a moderate increase in volatility after the turmoil whereas the break in variance is much higher when considering the second or the third value for $\sigma_{h}$. It also has to be noticed that under $D G P_{2}$, the break in variance occurs with a synchronous shift in the conditional correlation. A change to a regime of high volatility defines thus, as in Rodriguez (2007), the possible birth of a contagion phenomenon. Again, the null hypothesis of the test is that the correlation during the post-crisis period is equal to the correlation during the pre-crisis period, the alternative being that correlation increases. Correlation is corrected in the way suggested by Forbes and Rigobon (2002) to get the unconditional correlation coefficient and a standard one-sided $t$-test as the test statistics. The rejection frequency of the null hypothesis (i.e. detection of an increase in correlation, or contagion) is reported in Table (3). For large changes in correlation $\rho_{h}=0.7$ or 0.9 , the test correctly finds a structural break (i.e. rejects constant correlation) as the power is quite large. Nevertheless, when the increase in correlation is only moderate, or when the variance increase is rather strong, the 
power of the tests sharply decreases and the null hypothesis of constant correlation is no longer rejected. The relative location of the date of the break is also important, as it turns out that the power is maximum when $T_{b}=0.5$, and decreases as it is closer to the border.

Thus, when the data is generated by a copula based DGP similar to $D G P_{2}$, using unconditional correlations robust to a change in variance as in Forbes and Rigobon (2002) leads to an over acceptatance of the null hypothesis of no contagion. This bias becomes stronger as the correlation change is small, when the increase in variance is large and when the break is close to the sample borders. 


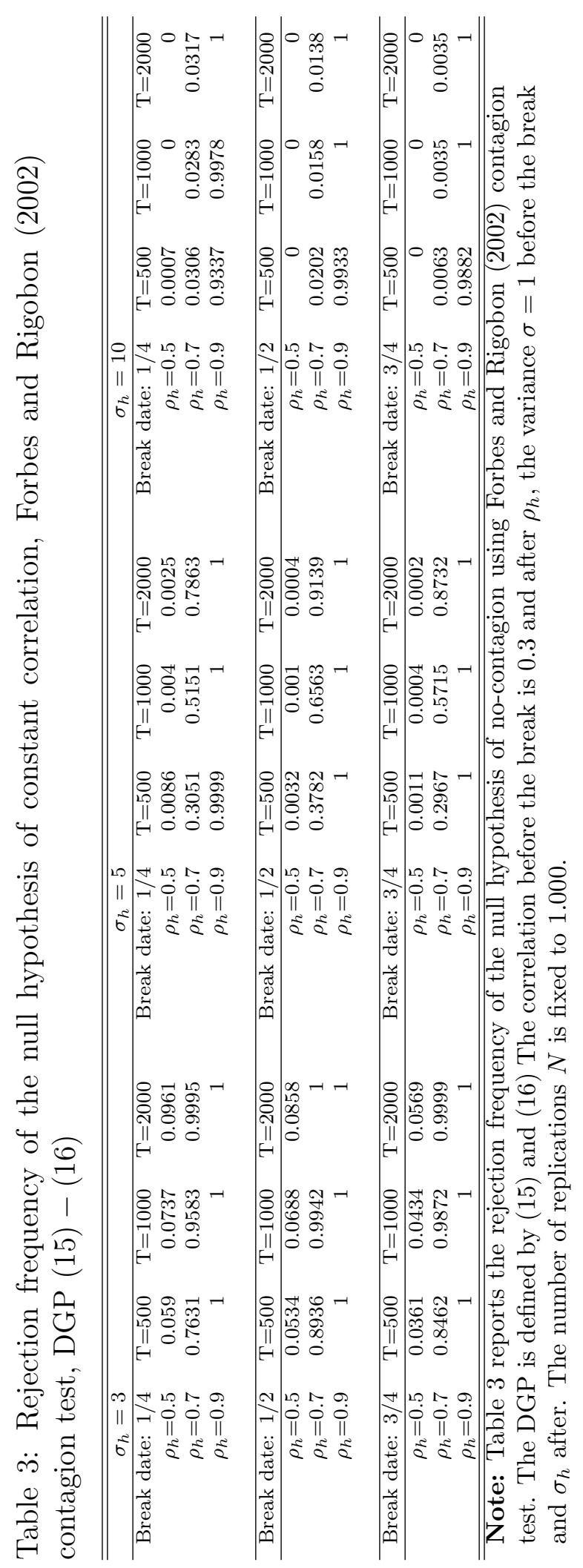




\subsection{Monte Carlo Study 3}

In this third Monte-carlo exercise, the data are generated as in the previous simulations by a Gaussian copula. Similarly, there is a breakpoint in the correlation parameter at a date $T_{b}\left(T_{b}=(0.25,0.5,0.75)\right)$, but we also allow the presence of a break in the variance of the individual series $V_{b}$, which takes place at a different date, i.e $T_{b} \neq V_{b}$. Such a differentiation between the breaks in the correlation and in the variance was not performed in the previous exercises, where we assumed $T_{b}=V_{b}$. The breaks in variance and correlation are estimated sequentially using the all-in-one algorithm presented in Section 2. Similar to the Monte-Carlo study 1 , a dummy $D_{2}$ is created to distinguish the periods before and after the estimated correlation break. The marginal series before and after the variance breaks are transformed beforehand using the empirical probability integral transform. The simulations have the same characteristics as the previous ones except that the correlation and the variance breaks are separated, both taking a different value in $(0.25,0.5,0.75)$. In Table $(3)$ we record both the rejection frequency of the null hypothesis of constant correlation conditional on the presence of a break in variance (absence of contagion) as well as the $95 \%$ confidence interval for the estimated correlation breaks.

The rejection frequencies of the sequential copula test, which are to be found in Table (3), indicate good power of the procedure to identify a structural break in correlation despite the nuisance caused by estimating the breaks in variance as well. Not surprisingly, the power of the procedure and the precision of the confidence intervals increase proportionally to the sample size and the size of the change in correlation after the turmoil. The point of the variance break does not seem to make a difference, nor whether the variance break occurs at the same time as the break in correlation. The sequential copula test seems to outperform the other procedures in all the cases as it is able to distinguish the break in variance from the one affecting correlation.

\section{Empirical Application}

The financial turmoil that has affected Asian countries in 1997 has fueled the empirical literature on contagion (see Dungey et al or Candelon et al, 2008). Its main feature is that Asian countries were assumed to be well behaved, i.e. to possess good macroeconomic 
Table 4: Rejection frequency of the null hypothesis of constant correlation, sequential copula contagion test

\begin{tabular}{|c|c|c|c|c|}
\hline \multicolumn{5}{|c|}{ Correlation break: $1 / 4$} \\
\hline Variance & break: $1 / 4$ & $\mathrm{~T}=500$ & $\mathrm{~T}=1.000$ & $\mathrm{~T}=2.000$ \\
\hline & \multirow{2}{*}{$\rho_{h}=0.5$} & 0.764 & 0.939 & 0.996 \\
\hline & & {$[0.154,0.771]$} & {$[0.174,0.497]$} & {$[0.191,0.33]$} \\
\hline & \multirow[t]{2}{*}{$\rho_{h}=0.7$} & 0.998 & 1 & 1 \\
\hline & & {$[0.205,0.296]$} & {$[0.224,0.271]$} & {$[0.236,0.259]$} \\
\hline & \multirow{2}{*}{$\rho_{h}=0.9$} & 1 & 1 & 1 \\
\hline & & {$[0.236,0.506]$} & {$[0.243,0.258]$} & {$[0.247,0.254]$} \\
\hline \multirow[t]{7}{*}{ Variance } & break: $1 / 2$ & $\mathrm{~T}=500$ & $\mathrm{~T}=1.000$ & $\mathrm{~T}=2.000$ \\
\hline & \multirow{2}{*}{$\rho_{h}=0.5$} & 0.726 & 0.907 & 0.989 \\
\hline & & {$[0.158,0.771]$} & {$[0.177,0.503]$} & {$[0.188,0.349]$} \\
\hline & \multirow{2}{*}{$\rho_{h}=0.7$} & 0.995 & 1 & 1 \\
\hline & & {$[0.211,0.294]$} & {$[0.224,0.27]$} & {$[0.236,0.258]$} \\
\hline & \multirow{2}{*}{$\rho_{h}=0.9$} & 1 & 1 & 1 \\
\hline & & {$[0.238,0.256]$} & {$[0.244,0.253]$} & {$[0.247,0.251]$} \\
\hline \multirow[t]{7}{*}{ Variance } & break: $3 / 4$ & $\mathrm{~T}=500$ & $\mathrm{~T}=1.000$ & $\mathrm{~T}=2.000$ \\
\hline & \multirow{2}{*}{$\rho_{h}=0.5$} & 0.715 & 0.908 & 0.989 \\
\hline & & {$[0.158,0.783]$} & {$[0.181,0.593]$} & {$[0.191,0.35]$} \\
\hline & \multirow{2}{*}{$\rho_{h}=0.7$} & 0.994 & 1 & 1 \\
\hline & & {$[0.212,0.288]$} & {$[0.225,0.269]$} & {$[0.237,0.258]$} \\
\hline & \multirow{2}{*}{$\rho_{h}=0.9$} & & 1 & 1 \\
\hline & & {$[0.238,0.256]$} & {$[0.244,0.253]$} & {$[0.247,0.251]$} \\
\hline \multicolumn{5}{|c|}{ Correlation break: $1 / 2$} \\
\hline Variance & break: $1 / 4$ & $\mathrm{~T}=500$ & $\mathrm{~T}=1.000$ & $\mathrm{~T}=2.000$ \\
\hline & $\rho_{h}=0.5$ & 0.857 & 0.99 & 0.999 \\
\hline & & {$[0.256,0.771]$} & {$[0.355,0.634]$} & {$[0.427,0.564]$} \\
\hline & $\rho_{h}=0.7$ & 1 & 1 & 1 \\
\hline & & {$[0.446,0.542]$} & {$[0.478,0.52]$} & {$[0.488,0.508]$} \\
\hline & $\rho_{h}=0.9$ & & 1 & 1 \\
\hline & & {$[0.488,0.52]$} & {$[0.494,0.503]$} & {$[0.497,0.501]$} \\
\hline Variance & break: $1 / 2$ & $T=500$ & $\mathrm{~T}=1.000$ & $\mathrm{~T}=2.000$ \\
\hline & $\rho_{h}=0.5$ & 0.864 & 0.972 & 0.999 \\
\hline & & {$[0.223,0.763]$} & {$[0.363,0.649]$} & {$[0.424,0.562]$} \\
\hline & $\rho_{h}=0.7$ & 1 & 1 & 1 \\
\hline & & {$[0.442,0.544]$} & {$[0.474,0.524]$} & {$[0.487,0.509]$} \\
\hline & $\rho_{h}=0.9$ & 1 & 1 & 1 \\
\hline & & {$[0.486,0.517]$} & {$[0.493,0.509]$} & {$[0.496,0.504]$} \\
\hline Variance & break: $3 / 4$ & $T=500$ & $\mathrm{~T}=1.000$ & $\mathrm{~T}=2.000$ \\
\hline & $\rho_{h}=0.5$ & 0.823 & 0.961 & 0.999 \\
\hline & & {$[0.248,0.78]$} & {$[0.356,0.655]$} & {$[0.432,0.554]$} \\
\hline & $\rho_{h}=0.7$ & 0.999 & 1 & 1 \\
\hline & & {$[0.44,0.538]$} & {$[0.475,0.516]$} & {$[0.487,0.509]$} \\
\hline & $\rho_{h}=0.9$ & 1 & 1 & 1 \\
\hline & & {$[0.488,0.518]$} & {$[0.494,0.503]$} & {$[0.497,0.501]$} \\
\hline Correlation & break: $3 / 4$ & & & \\
\hline Variance & break: $1 / 4$ & $\mathrm{~T}=500$ & $\mathrm{~T}=1.000$ & $\mathrm{~T}=2.000$ \\
\hline & $\rho_{h}=0.5$ & 0.788 & 0.954 & 0.997 \\
\hline & & {$[0.221,0.832]$} & {$[0.429,0.824]$} & {$[0.662,0.802]$} \\
\hline & $\rho_{h}=0.7$ & 1 & 1 & 1 \\
\hline & & {$[0.694,0.784]$} & {$[0.724,0.768]$} & {$[0.738,0.759]$} \\
\hline & $\rho_{h}=0.9$ & 1 & 1 & 1 \\
\hline & & {$[0.738,0.756]$} & {$[0.744,0.752]$} & {$[0.747,0.751]$} \\
\hline Variance & break: $1 / 2$ & $\mathrm{~T}=500$ & $T=1.000$ & $\mathrm{~T}=2.000$ \\
\hline & $\rho_{h}=0.5$ & 0.793 & 0.939 & 0.998 \\
\hline & & {$[0.262,0.833]$} & {$[0.414,0.824]$} & {$[0.663,0.804]$} \\
\hline & $\rho_{h}=0.7$ & 1 & 1 & 1 \\
\hline & & {$[0.69,0.784]$} & {$[0.717,0.768]$} & {$[0.737,0.759]$} \\
\hline & $\rho_{h}=0.9$ & 1 & 1 & 1 \\
\hline & & {$[0.736,0.756]$} & {$[0.744,0.753]$} & {$[0.747,0.751]$} \\
\hline Variance & break: $3 / 4$ & $\mathrm{~T}=500$ & $\mathrm{~T}=1.000$ & $\mathrm{~T}=2.000$ \\
\hline & $\rho_{h}=0.5$ & 0.784 & 0.938 & 0.996 \\
\hline & & {$[0.253,0.835]$} & {$[0.533,0.825]$} & {$[0.668] 0.801$,} \\
\hline & $\rho_{h}=0.7$ & 1 & 1 & 1 \\
\hline & & {$[0.688,0.788]$} & {$[0.724,0.768]$} & {$[0.736,0.76]$} \\
\hline & $\rho_{h}=0.9$ & 1 & 1 & \\
\hline & & {$[0.735,0.769]$} & {$[0.743,0.76]$} & {$[0.746,0.754]$} \\
\hline
\end{tabular}

Note: Table 4 reports the rejection frequency of the null hypothesis of no-contagion using the sequential copula contagion test. The correlation before the break is 0.3 and after $\rho_{h}$, the variance $\sigma=1$ before the break and $\sigma_{h}=5$ after. The number of replications $N$ is fixed to 1.000 . The $95 \%$ confidence bound for the estimated location of break is inficated between brackets. 
fundamentals, before the occurrence of the crisis, leaving market analysts or modelers of the first generation without any voice. The importance of the transmission of the crisis from Thailand, which was first hit, to the rest of Asia is therefore at the core of this global crisis. The conclusion of Forbes and Rigobon (2002), rejects the presence of contagion in this crisis, and has let analysts skeptical. ${ }^{24}$ Our Monte-Carlo experiments have shown that this test tends to over accept the null hypothesis of no contagion when the DGP is copula based. A traditional copula-based test like the one Rodriguez (2007) is therefore preferred. However, it may be biased if the break in variance and correlation are erroneously assumed to be identical. In such a case the sequential procedure based on time-varying copula presented in section 2 turns out to be the best alternative. In this empirical application, stock returns for eight Asian countries ${ }^{25}$ are considered. Series are daily, extracted from Datastream market indices, labeled in $U S \$$ and cover the period 01/01/1996 - 30/06/1998, i.e. 652 observations. Returns of the market indices are plotted in Figure (1). To shed new light on the question of the possible contagious characteristic of the Asian crisis, the sequential algorithm, presented in Section 2.5, is applied. We consider both Thailand and Hong Kong as the "ground-zero" countries at the origin of the financial crisis. It is well-documented in the literature (see for example Dungey et al. 2006) that the Asian crisis was first initiated by the Thai Baht devaluation, and then by the crash of the Hong Kong stock market. These shocks have to be analyzed separately to draw a global picture of the shift-contagious process during the Asian crisis.

For each bivariate system of the other 6 Asian countries with both Thailand and Hong Kong (i.e. 13 models), we estimate the VAR given in model (5) and then the steps $1-7$ are performed on the residuals. ${ }^{26}$ Table (5) reports the dates for the structural breaks found in all univariate systems, and Table (6) gathers the dates for the structural breaks in the conditional copula, together with confidence intervals, which together should allow for a conclusion whether contagion has occurred. It first turns out that point estimates for the dates

\footnotetext{
${ }^{24}$ Some other empirical papers extending the Forbes and Rigobon (2002)'s test reach a different conclusion. See Corsetti et al, 2005 and Candelon et al 2005.

${ }^{25}$ These countries are Thailand, Malaysia, Japan, Hong-Kong, Taiwan, Indonesia, Korea and the Philippines.

${ }^{26}$ The study is limited to bivariate systems in order to avoid the possible effect of indirect contagion or third-country effects. The Johansen Cointegration tests reject the presence of cointegration relationship for the bivariate systems composed by the indices, allowing us to specify the VAR with the return series. Furthermore, optimal lag length is determined according to the Schwarz information criterion.
} 
Figure 1: Returns series
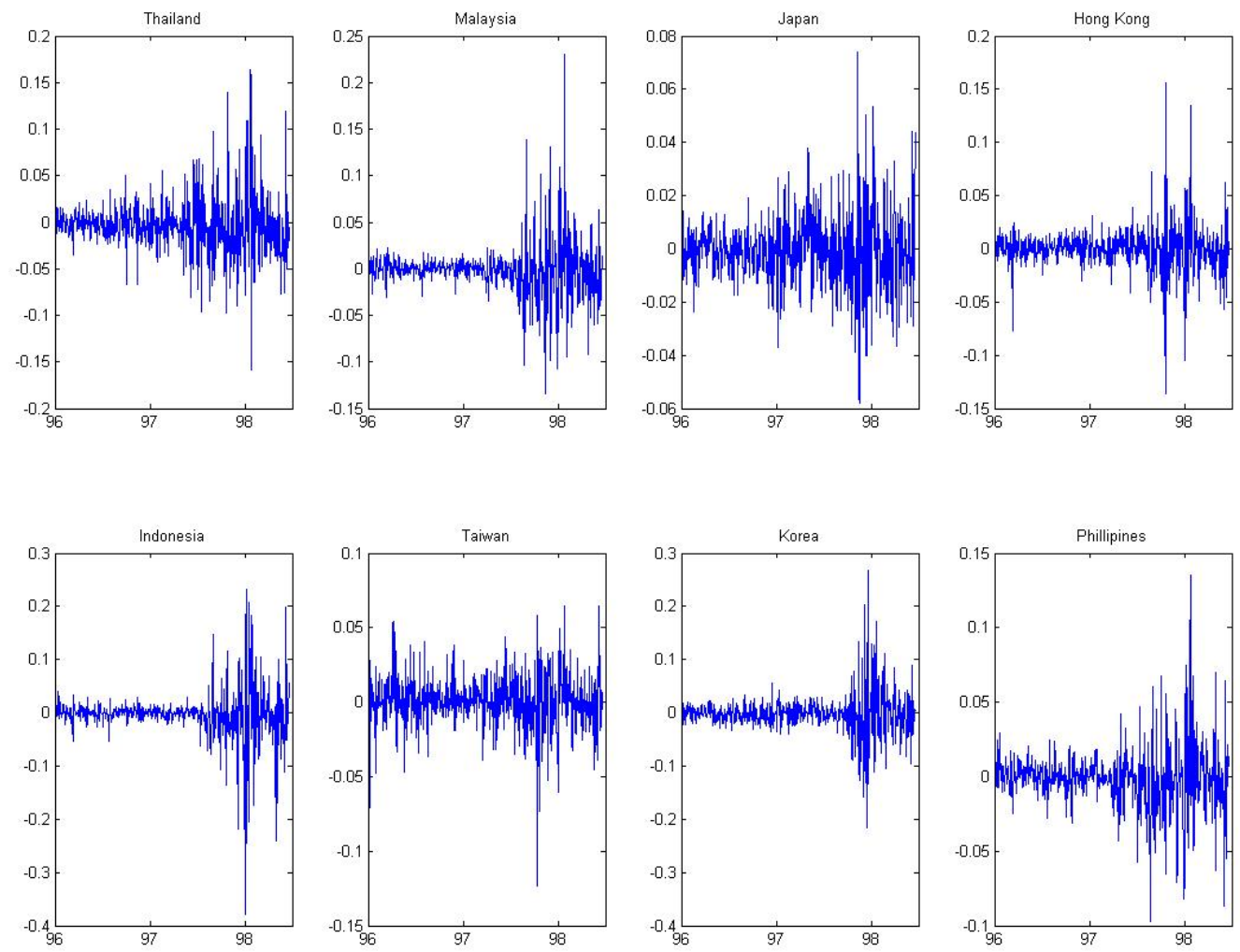
of the break in variance generally precede the ones from of the conditional correlations. ${ }^{27}$ There are two cases, one where the confidence intervals of the variance and correlation breaks overlap and one where they do not. The assumption of concomitance between the change in volatility and dependence is thus not always supported. It thus supports the intuition that some time exists between the occurrence of the crisis, the increase in volatility and its spill-over developments. This delay finds its justification in the time for information to be spread over the region. Moreover, such a result justifies our sequential testing procedure. Referring to the second Monte-Carlo exercise, a copula based test assuming erroneously a same break in variance and in conditional correlation would result in an over-rejection of the null hypothesis of no break leading to the fallacious conclusion of a contagious transmission of the crisis. It may be a reason why Rodriguez (2007) supports this conclusion for all the bivariate systems of Asian countries. This result also contradicts the ones in Forbes and Rigobon (2002) which are biased towards the null hypothesis of no contagion. In our case, we have a mixed result as two systems, (Hong Kong; Japan) and (Hong Kong; Korea) do not exhibit any significant change in conditional correlation, leading to the rejection of a contagious transmission of the Asian crisis. It is nevertheless clear that these two systems are a minority compared to the 11 other exhibiting a significant break. Thus, the main picture delivered by our study is clearly in favor of the existence of contagious characteristics of the Asian 1997 crisis.

Next, a loglikelihood ratio test is used to evaluate the relative significance of the volatility and the correlation regime (characterized by two different dummies) in the time-varying copula parameter. To this aim the conditional mean is modeled via a VAR model given in (2). The conditional variance $h_{t}$ of the errors $\epsilon_{t}$ is modeled by a t-GARCH, which can be stated as

$$
h_{t}=\omega_{t}+\alpha_{1} \epsilon_{t-1}^{2}+\alpha_{2} h_{t-1},
$$

where the standardized innovations $\nu_{t}=\sqrt{\frac{\kappa}{h_{t}(\kappa-2)}} \nu_{t} \sim t_{\kappa}$. The $\nu_{t}$ 's are modeled by a semiparametric gaussian copula model, where the correlation parameter is allowed to vary over

\footnotetext{
${ }^{27}$ Asidesfrom comparison of break dates in the variance and the conditional correlation, the "U-shape" form of the conditional correlations, which is plotted in figure 3 constitutes another support for this conclusion.
} 
time conditional on a set of variables. Formally,

$$
\left(\begin{array}{c}
v_{1 t} \\
v_{2 t}
\end{array}\right) \mid \Omega_{t-1} \rightsquigarrow C^{\text {Gaussian }}\left(\hat{F}\left(v_{1}\right), \hat{F}\left(v_{2}\right) ; \rho_{t}\right),
$$

where $\hat{F}$ denotes the empirical probability integral transform. Recall that $p$ is the breakpoint in variance of the "ground-zero" country and $k$ is the break of the copula parameter estimated previously. Define two dummies $D_{t}(\rho)$ and $D_{t}(\sigma)$ as: $D_{t}(\sigma)=0$ for $t<p, D_{t}(\sigma)=1$ for $t \geq p, D_{t}(\rho)=0$ for $t<k$ and $D_{t}(\rho)=1$ for $t \geq k$. Then $\rho_{t}$ evolves over time according to

$$
\rho_{t}=\Lambda\left(\alpha+\beta_{1} \cdot D_{t}(\sigma)+\beta_{2} \cdot D_{t}(\rho)\right)
$$

where $\Lambda(x)=\frac{1-e^{-x}}{1+e^{-x}}$ is the modified logistic transformation to keep $\rho$ in $(-1,1) .{ }^{28}$ We test the two restrictions that one of the two dummies is not significant, given the other is included in the model. Formally, the sequence of hypotheses is the following one:

$H_{0}^{a}: \beta_{2}=0$

and

$H_{0}^{b}: \beta_{1}=0$

against:

$H_{1}: \beta_{1} \neq 0$ and $\beta_{2} \neq 0$

The p-values for the tests are given in table (7). In almost all the cases, $H_{0}^{a}$ is rejected against $H_{1}$, indicating that the correlation dummy improves the model when the variance dummy is included. However, $H_{0}^{b}$ is rejected in favor of $H_{1}$ only in a few cases. The presence of a dummy for the variance hence is not found to be significant when a correlation break dummy is already in the model. Taken together these results support the previous finding of shift-contagion, irrespective of the presence of a change in volatility.

\footnotetext{
${ }^{28}$ The conditional variance estimated from a GARCH model can also be used as the measure for volatility instead of the dummy. The results were very similar to the ones presented here and are available upon request.
} 
Figure 2: GARCH Variances
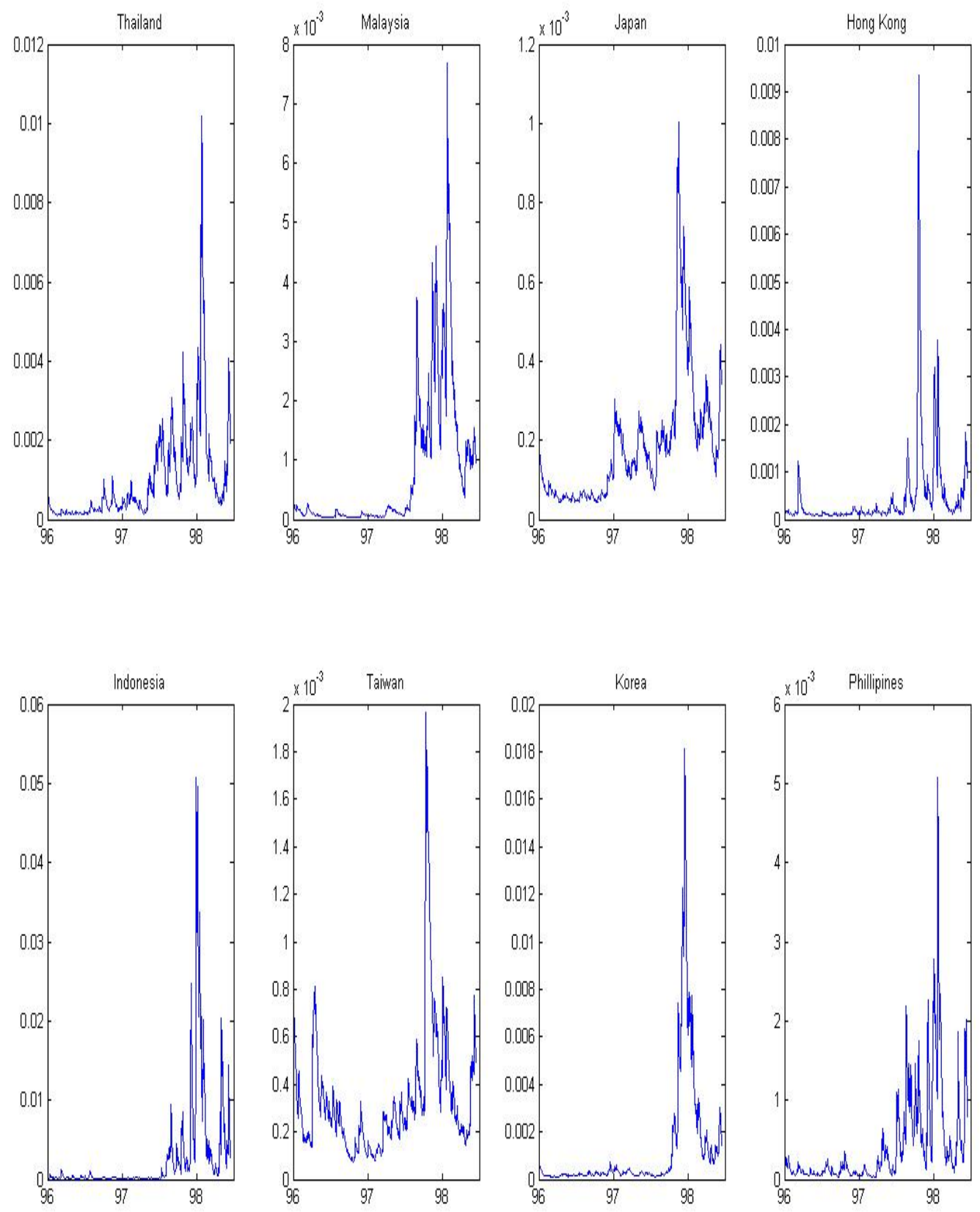
Table 5: Breakpoints in variance.

\begin{tabular}{rr}
\hline \hline Thailand & $12-5-1997$ \\
& {$[24-4-1997,2-6-1997]$} \\
$30-7-1997$ \\
Malaysia & {$[28-7-1997,6-8-1997]$} \\
$3-12-1996$ \\
Japan & {$[22-11-1996,26-12-1996]$} \\
$20-10-1997$ \\
Japan second break & {$[1-9-1997,5-2-1998]$} \\
& $15-8-1997$ \\
Hong Kong & {$[14-7-1997,5-9-1997]$} \\
& $12-8-1997$ \\
Indonesia & {$[5-8-1997,18-8-1997]$} \\
$18-7-1997$ \\
Taiwan & {$[24-1-1997,8-12-1997]$} \\
$13-10-1997$ \\
Korea & {$[9-10-1997,22-10-1997]$} \\
$18-4-1997$ \\
Philippines \\
\end{tabular}

Note: This table reports the date of the structural break in volatility found using the sequential approach, describe in Section 2.4. Confidence bounds are bootstrapped (1.000 replications) and indicated between brackets. 

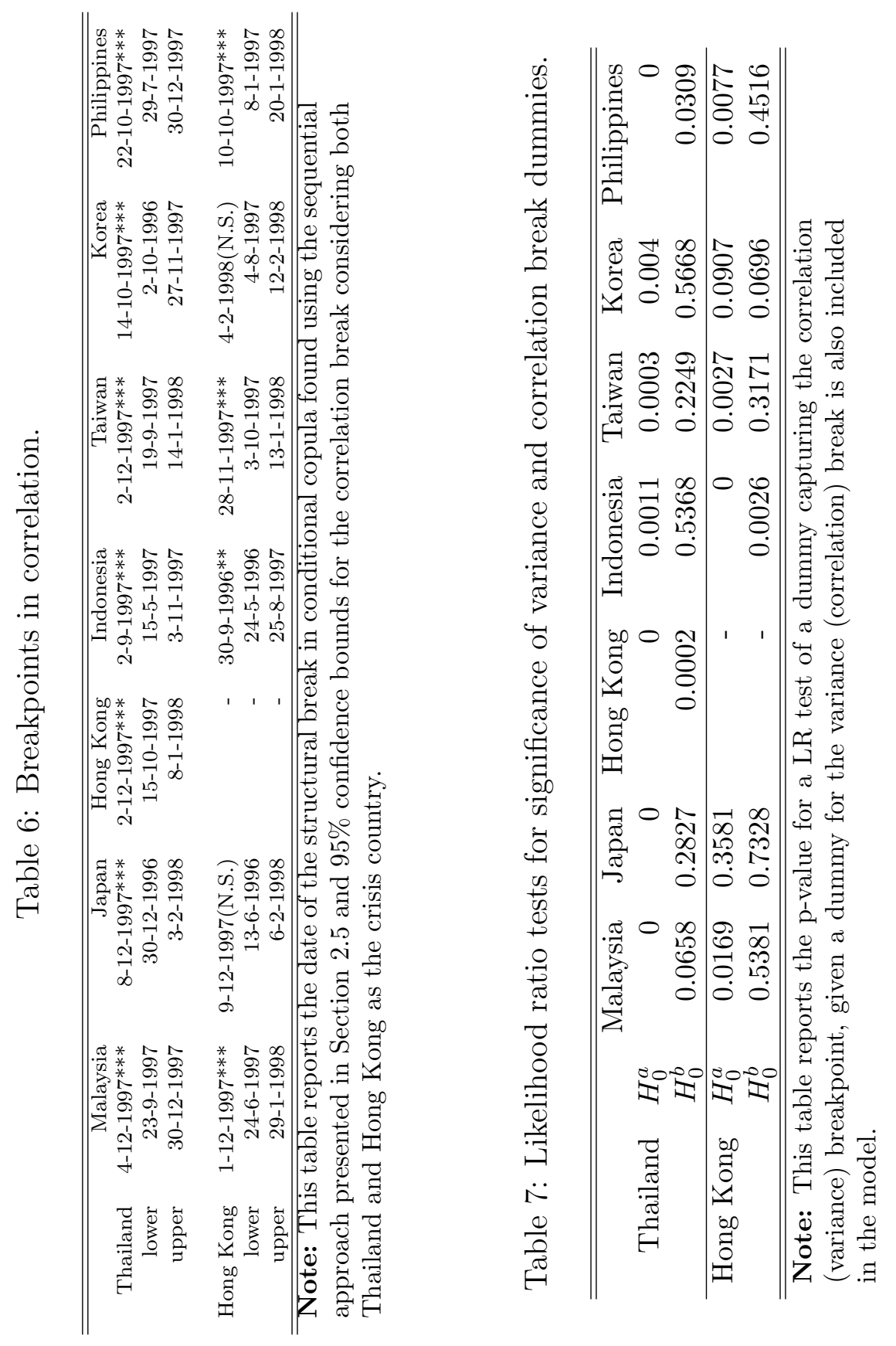
As a final step in our analysis we use conditional copulas to model the path of the correlation coefficient of a Gaussian copula for the standardized VAR-tGARCH residuals, transformed by the empirical distribution function. To this end the correlation coefficient evolves as proposed in Patton (2006a):

$$
\rho_{t}=\Lambda\left(\alpha+\beta_{1} \cdot \rho_{t-1}+\beta_{2} \cdot \frac{1}{p} \sum_{j=1}^{p} \Phi^{-1}\left(u_{t-j}\right) \cdot \Phi^{-1}\left(v_{t-j}\right)+\gamma \cdot Z_{t}\right)
$$

where, as before, $\Lambda(\cdot)$ is the modified logistic transformation. The number of lags of cross products is chosen such that the fit of the model is best. $Z$ is a set of additional conditioning variables. If $Z$ is exogenous the distribution of the marginals must also be conditioned on it. In our case, however, it will be the dummies capturing the breakpoint in correlation and variance we detected with our procedure above. Dummies are included depending on the results obtained with the likelihood ratio tests given in table (7). The GARCHvariance are reported in Figure 2, whereas the conditional correlations are plotted in Figure 3. One can see that conditional correlation vary quite a lot over time, increasing after the "correlation" break. The evolution of the conditional correlation after the "volatility break" show a more shadowed picture: On one hand, it turns out that dependence decreases for some system leading to a "U-shape" evolution of the conditional correlations. Such a shape remains difficult to explain, even if it is confirmed by other studies using different techniques (Cappiello et al, 2005). On the other hand, some pairs of countries exhibit a constant increase in the conditional correlation, stressing that dependence begins to increase with the volatility break. Nevertheless, Figures (2) and (3) support our previous conclusions that the break in variance generally precedes the one in correlation. This is thus further evidence that high volatility is not always concomitant to an increase in correlation.

The robustness of the previous results vis-⿳亠丷⿵冂-vis the data and the estimation method of the conditional copula has been checked. We consider filtering the series only by AR models (instead of VAR), with or without GARCH filtering, and a fully-parametric estimation of the copula (i.e. specifying the marginal distributions parametrically), without finding different qualitative results. ${ }^{29}$ The qualitative results are also quite robust to the choice of copula. ${ }^{30}$ In some particular cases, applying a different type of copula appears to outperform the

\footnotetext{
${ }^{29}$ Tables are not reported to save space but can be requested from the authors on request.

${ }^{30}$ Further copulas considered are the Student, Clayton, Frank and Gumbel copulas and mixtures of these.
} 
Gaussian copula. However, as the conclusions are not modified and the computing time explodes, we only report results for the Gaussian copula.

\section{Conclusion}

In this paper we propose a new sequential procedure using time varying copula to test for the presence of an increase in stock market dependence after a financial crisis, i.e. contagion process. We show that the previous approach proposed by Forbes and Rigobon (2002) to account for the effect of changes in volatility regime is biased toward the rejection of the contagion hypothesis when the DGP is non linear. Similarly, Rodriguez' (2007) approach, which analyzes the interdependence across volatility regimes, is also biased. It leads to an over acceptance of the contagion hypothesis at the wrong point in time, when the change in variance and conditional correlation regime is different. In order to offer a better approach, we develop a sequential algorithm, which allows for different breakpoints in the variance and the conditional correlation. Moreover, the proposed contagion test is a sequential "allin-one" procedure which takes into account the uncertainty in the determination of the variance regime. The formal stability test is elaborated from the one proposed by Dias and Embrechts (2004) and a bootstrap procedure is implemented in order to tackle the distortion in the asymptotic distribution due to the presence of breakpoint in the nuisance parameters. Applied to the recent 1997 Asian crisis, the results produced by our sequential algorithm support that assuming the same break date for the variance and the conditional correlation is an erroneous assumption: Breaks in variances are generally preceding those in conditional correlation. Nevertheless, the Asian crisis turns out to have been characterized by a regional contagious transmission of the Thai shock.

Beyond the separate analysis of the effect of the volatility regime on the evolution of asset market dependence, tail-dependence may be also interesting as a complementary measure for contagion (Rodriguez, 2007). Future research would include another step in the sequential procedure that would allow for lower tail dependence (see Joe, 1997, for a definition) as well as changing types of dependence over time (as studied by Rodriguez, 2007). This could be performed using a more flexible copula model that additionally allows for conditional tail dependence. Even if such an analysis would bring a complementary insight on the tail dependence time path, it would not modify the previous results. 

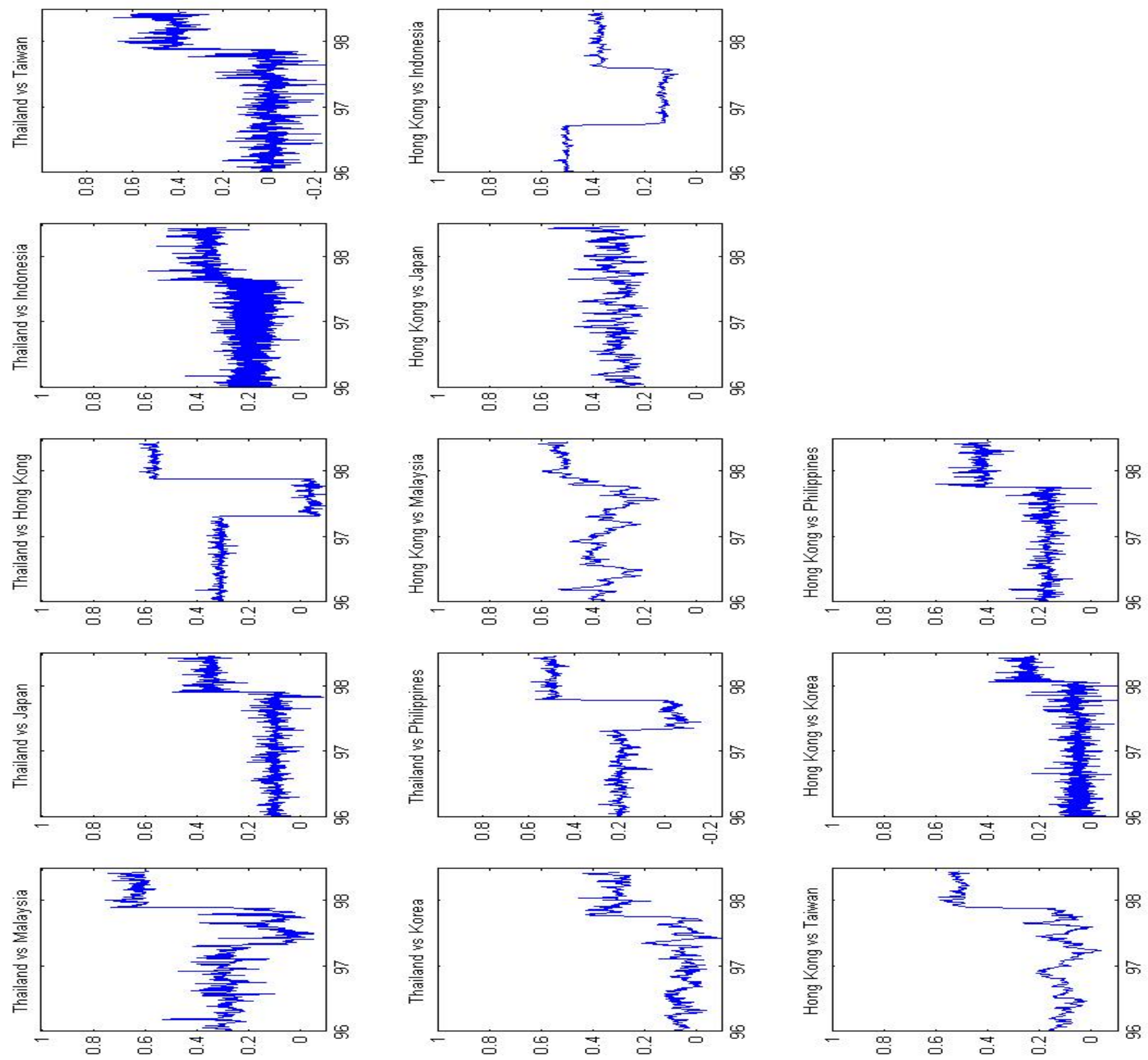


\section{References}

[1] Andrews, D.W.K. (1993), "Tests for Parameter Instability and Structural Change with Unknown Change Point", Econometrica, 61, 821-856.

[2] Ang, A. and G. Bekaert (2002), "International Asset Allocation with Regime Shifts", Review of Financial Studies, 15, 4, 1137-1187.

[3] Bae, K.-H., Karolyi, G.A., Stulz, R.M. (2003), "A New Approach to Measuring Financial Contagion", Review of Financial Studies 16, 717763.

[4] Baig, T. and I. Goldfajn (1998), "Financial Market Contagion in the Asian Crisis", IMF Working Paper, No. 98-155.

[5] Bonhomme, S. and J.-M. Robin (2006), "Modeling Individual Earnings Trajectories Using Copulas: France, 1990-2002", in Contributions to Economic Analysis, Vol. 275. "Structural Models of Wage and Employment Dynamics", edited by Henning Bunzel, Bent J. Christensen, George R. Neumann and Jean-Marc Robin.

[6] Calvo, S., and C.M. Reinhart (1995), "Capital Inflows to Latin America: Is there Evidence of Contagion Effects?" in Guillermo A. Calvo, Morris Goldstein, and Eduard Hochreiter, eds.: Private Capital Flows to Emerging Markets After the Mexican Crisis (Institute for Internatioanl Economics, Washington, DC).

[7] Candelon, B., and H. Lütkepohl (2001), "On the Reliability of Chow type Tests for Parameter Constancy in Multivariate Dynamic Models", Economics Letters, 73, 155160.

[8] Candelon, B., Hecq, A. and W. Verschoor (2005), "Measuring Common Cyclical Features During Financial Turmoil: Evidence of Interdependence not Contagion", Journal of International Money and Finance, 24, 1317-1334.

[9] Candelon, B., Piplack, J. and S. Streatmans (2008), "On Measuring Synchronization of Bulls and Bears: the Case of East Asia", Journal of Banking and Finance in press.

[10] Cappiello, L., Grard, B. and Manganelli, S. (2005) "Measuring Comovements by Regression Quantiles", ECB Working Paper July. 
[11] Chen, X. and Y. Fan (2006), "Estimation and Model Selection of Semiparametric Copula-based Multivariate Dynamic Models under Copula Misspecification," Journal of Econometrics, vol. 135, 125-154.

[12] Cherubini G., E. Luciano and W. Vecchiato (2004), Copula Methods in Finance, John Wiley and Sons Ltd.

[13] Corsetti, G., M. Pericoli, and M. Sbracia (2005), "Some Contagion, some Interdependence: More Pitfalls in Tests of Financial Contagion" Journal of International Money and Finance, 24, 1177-1199.

[14] Dias, A. and P. Embrechts (2004), "Change-Point Analysis for Dependence Structures in Finance and Insurance" in Risk Measures for the 21st Century, ed. by Giorgio Szegoe, Wiley Finance Series, Chapter 16, 321-335.

[15] Dungey, M., Fry, R., Martin, V. (2006), "Correlation, Contagion and Asian Evidence", Asian Economic Journal, forthcoming.

[16] Embrechts, P., A. McNeil and D. Straumann (2002), "Correlation and Dependence Properties in Risk Management: Properties and Pitfalls", in M. Dempster, ed., Risk Management: Value at Risk and Beyond, Cambridge University Press.

[17] Embrechts, P., F. Lindskog and A. McNeil (2003), "Modelling Dependence with Copulas and Applications to Risk Management", in Handbook of Heavy Tailed Distributions in Finance, Elsevier, Chapter 8, 329-384.

[18] Forbes, K.J., Rigobon, R., (2002), "No Contagion, only Interdependence: measuring Stock Market Co-movements", Journal of Finance 57 (5), 2223-2261.

[19] Genest, C., K. Ghoudi and L.-P. Rivest (1995), "A Semiparametric Estimation Procedure of Dependence Parameters in Multivariate Families of Distributions", Biometrika $82,543-552$.

[20] Gombay, E. and L. Horváth (1996), "On the Rate of Approximations for Maximum Likelihood Tests in Change-Point Models", Journal of Multivariate Analysis, 56(1), $120-152$. 
[21] Granger, C.W.J., T. Tersvirta and A. Patton (2006), "Common Factors in Conditional Distributions", Journal of Econometrics, 132(1), 43-57.

[22] Hartman, P, S. Straetmans and C. de Vries (2004) "Asset Market Linkages in Crisis Periods", Review of Economics and Statistics, 86 (1), 313-326.

[23] Joe, H. and J.J. Xu (1996), "The Estimation Method of Inference Functions for Margins for Multivariate Models", Department of Statistics, University of British Colombia, Technical Report 166.

[24] Joe, H. (1997), Multivariate Models and Dependence Concepts, Chapman \& Hall/CRC.

[25] Junker, M. and A. May (2005), "Measurement of Aggregate Risk with Copulas", Econometrics Journal, Vol. 8(3), 428-454.

[26] King, M. and S. Wadhwani (1990), "Transmission of Volatility Between Stock Markets", Review of Financial Studies, Vol. 3, pp. 3-33.

[27] Lee, S.B., and Kwang J.K., (1993), "Does the October 1987 crash strengthen the comovements among national stock markets?", Review of Financial Economics 3, 89-102.

[28] Masson, P.R., (1999), "Contagion: Monsoonal Effects, Spillovers, and Jumps Between Multiple Equilibria", in Agnor, P., Miller, M. and Vines, D. (eds), The Asian Crises: Causes, Contagion and Consequences, Cambridge: Cambridge University Press.

[29] Nelsen, R.B. (2006), An Introduction to Copulas, Springer.

[30] Okimoto, T. (2007), "New Evidence of Asymmetric Dependence Structures in International Equity Markets", Journal of Financial and Quantitative Analysis, forthcoming.

[31] Patton, A. (2006a), "Modelling Asymmetric Exchange Rate Dependence", International Economic Review, 47(2), 527-556.

[32] Patton, A. (2006b), "Estimation of Multivariate Models for Time Series of Possibly Different Lengths", Journal of Applied Econometrics, 21(2), 147-173.

[33] Pesaran H. and Pick, A., (2007) "Econometric Issues in the Analysis of Contagion" Journal of Economic Dynamics and Control 31, 1245-1277. 
[34] Ramchand L. and Susmel, R. (1998), "Volatility and Cross Correlation across Major Stock Markets", Journal of Empirical Finance 5, 397-416.

[35] Rodriguez, J.C. (2007), "Measuring Financial Contagion: A Copula Approach", Journal of Empirical Finance, 14(3), 401-423.

[36] Straetmans, S. (1997), "Extreme financial returns and their comovements", PhD thesis Tinbergen Institute, n181. 